\title{
Inaugurating the Everett Mendelsohn Prize
}

\author{
MICHAEL R. DIETRICH \\ Department of Biological Sciences \\ Dartmouth College \\ Hanover, $\mathrm{NH}$ \\ USA \\ E-mail:michael.dietrich@dartmouth.edu
}

It is my pleasure to announce the inauguration of the Everett Mendelsohn Prize. This prize will be awarded annually to the author of an article published during the previous 3 years in the Journal of the History of Biology. Every article published in the preceding 3 years will be automatically considered. The Editor-in-Chief and the Associate Editors of $J H B$ will act as a committee to award the prize, and will judge all entries on the basis of their originality, scholarship, and significance for the history of biology. Each year's winner will be announced in $J H B$, and will receive an honorarium of $\$ 500$. The first Everett Mendelsohn Prize will be awarded in 2017 to mark the 50th volume of the journal. All articles published in $J H B$ in 2014-2016 (volumes 47-49) will be considered for this first Mendelsohn Prize.

As the journal reaches its 50th volume, it is appropriate to recognize the many contributions of its founder with this prize. Everett began the Journal of the History of Biology in 1968. For its first 31 years, he oversaw JHB's publication and in doing so shaped the scholarly foundations for the field of history of biology. Everett joined the faculty in the Department of the History of Science at Harvard University in 1960, where he remains as an Emeritus Professor today. Over the course of his career, he wrote and edited or coedited an impressive array of books and articles including Heat and Life: The Development of the Theory of Animal Heat (1964), Human Aspects of Biomedical Innovation (1971), Sciences and Cultures: Anthropological and Historical Studies of the Sciences (1981), Transformation and Tradition in the Sciences: Essays in Honor of I. Bernard Cohen (1984), Science, Technology, and the Military (1988), Technology, Pessimism and Postmodernism (1993), Biology as Society, Society as Biology: Metaphors (1994), The Practices of Human 
Genetics (1999), and Science in Culture (2001). As Everett's many students will attest, he is also a superb mentor and teacher. The same insight, patience, and support benefitted generations of historians who published their work in $J H B$. Those of us whose first articles appeared here will be forever grateful to Everett for his hard work guiding our scholarship through review and revision toward eventual publication. Creating $J H B$ as a scholarly venue and then fostering the hundreds of articles and reviews that have filled its pages has had an immeasurable, lasting, and profoundly positive effect on our field and the history, philosophy, and sociology of science more generally.

It is an honor to be able recognize Everett's lasting contribution to the history of biology, and inaugurate this prize in his name. 